\title{
Fabrication of a layered hybrid membrane using an organosilica separation layer on a porous polysulfone support, and the application to vapor permeation
}

Genghao Gong, Jinhui Wang, Hiroki Nagasawa, Masakoto Kanezashi, Tomohisa Yoshioka, and Toshinori Tsuru*

Department of Chemical Engineering, Hiroshima University, 1-4-1 Kagayami-yama, Higashi-Hiroshima 739-8527, Japan

*Corresponding author: Tel.: +81 82424 7714, Fax: +81 824227191

E-mail: tsuru@hiroshima-u.ac.jp

\begin{abstract}
Using 1,2-bis(triethoxysilyl)ethane (BTESE) as a single precursor, a uniform, defect-free and perm-selective organosilica layer was successfully deposited onto porous polysulfone ultrafiltration (PSF-UF) supports via a simple sol-gel spin-coating and thermal-treatment process. The layered hybrid membranes, where BTESE-derived $\mathrm{SiO}_{2}$ is deposited on polymer supports, were applied to the vapor permeation dehydration of isopropanol-water (90/10 wt $\%)$ solutions at $105{ }^{\circ} \mathrm{C}$, and demonstrated a water flux of $1.6 \mathrm{~kg} /\left(\mathrm{m}^{2} \mathrm{~h}\right)$ and a separation factor of 315 with no selectivity for a PSF-UF support. Long-term stability testing of vapor permeation also confirmed the excellent stability of these BTESE/PSF-UF layered hybrid membranes. Moreover, compared with porous PSF-UF supports, this layered hybrid membrane also showed improved gas separation performance and a moderate $(\approx 10)$ separation factor for $\mathrm{H}_{2} / \mathrm{N}_{2}$.
\end{abstract}

Keywords: Hybrid organosilica, layered hybrid, Porous polysulfone, Spin coating, Vapor permeation

\section{Introduction}

(C) 2014. This manuscript version is made available under the Elsevier user license http://www.elsevier.com/open-access/userlicense/1.0/ 
Membrane separation processes are recognized as one of the most promising separation technologies with energy consumption and operating costs that are both low by comparison with that of conventional separation processes such as distillation [1]. Currently, the improvements in membrane separation technology are mainly focused on the development of advanced separation membranes and the optimization of different membrane processes through process integration $[2$, 3]. The fabrication of advanced separation membranes is one of the most important factors and is attracting great interest. Generally, the separation performance of a membrane is intrinsically determined by the structure and characteristics of the membrane material [4]. Moreover, most membranes are composed of multiple layers with different functions and properties. Only the active top layer plays a vital role, whereas other layers simply act as a mechanical support [5].

A specific example of this active layer would be a hybrid organosilica membrane, which is composed of covalently bonded organic and inorganic moieties. This new class of silica membrane is attracting an ever-increasing amount of attention due to outstanding properties such as excellent hydrothermal stability [6] and silica networks with adjustable pore sizes [7]. For example, a promising organosilica membrane prepared via a sol-gel process using a bridged precursor, 1,2-bis(triethoxysilyl)ethane (BTESE), has shown excellent stability (at least 2 years) in the dehydration of n-butanol at $150^{\circ} \mathrm{C}$ [8]. In our previous report, we described the successful development of silica networks using BTESE that resulted in a highly permeable hydrogen separation layer with hydrothermal stability [9]. Subsequently, our research group applied BTESE membranes to the dehydration of acetic acid aqueous solutions in the pervaporation and desalination of $1,500 \mathrm{ppm} \mathrm{NaCl}$ aqueous solutions via reverse osmosis as well as confirming an excellent stability in both acid [10] and chlorine [11], respectively, along with a superior molecular sieving ability. Both excellent stability and high separation performance have been ascribed to Si-C-C-Si units. The BTESE membrane showed a stable pervaporation flux and separation factor for more than 10 hours even when prepared at a calcination temperature as low as $100{ }^{\circ} \mathrm{C}$ [12]. Analogously, potential hybrid organosilica membranes with different bridge and pendant groups have been reported [13-15]. However, all the organosilica membranes were prepared on inorganic supports such as porous $\mathrm{Al}_{2} \mathrm{O}_{3}$ supports with a pore size of approximately $200 \sim 1000 \mathrm{~nm}$ [6-18]. The cost of these ceramic membranes will always be higher than that of polymer-based ones [19]. 
Therefore, organosilica- $\mathrm{Al}_{2} \mathrm{O}_{3}$ membranes with complex fabrication processes [20] and high cost may not be suitable for large-scale industrial utilization. To overcome this potential disadvantage, a new approach to the application of hybrid organosilica layers using a relatively low-cost polymeric support was proposed, almost simultaneously, by Ngamou et al. and our research group via an expansion of thermal plasma chemical vapor deposition (ETP-CVD) [21] and a sol-gel spin-coating process [22], respectively. The former requires sophisticated equipment and rigorous conditions in order to deposit a BTESE-derived CVD layer onto a polyamide-imide support for the retention of organic bridges. More importantly, the structure of BTESE was partially decomposed due to the high-energy state of plasma during this process. Reportedly, only $30 \%$ of the $\mathrm{Si}_{-} \mathrm{C}_{2} \mathrm{H}_{4}-\mathrm{Si}$ bridges were retained in the silica network, which may degrade the stability of the hybrid membranes.

Therefore, we proposed a layered hybrid membrane by sol-gel processing, where an organosilica layer would be coated onto a polysulfone (PSF) support via simple sol-gel spin coating, and thereby all the $\mathrm{Si}_{-} \mathrm{C}_{2} \mathrm{H}_{4}-\mathrm{Si}$ bridges could be retained in BTESE layer networks. More importantly, the flexibility of these organic bridge groups $\left(\mathrm{Si}-\mathrm{C}_{2} \mathrm{H}_{4}-\mathrm{Si}\right)$ resulted in a BTESE layer with a polymeric character and excellent fracture resistance [23], thereby improving the flexibility of a PSF-supported BTESE layered hybrid membrane, which is one of the most important factors for scale-up. The layered hybrid membranes consisted of an inorganic separation layer on a polymeric support and show promise for the fabrication of high-performance, light-weight membranes with low production cost, which would be suitable for large-scale industrial applications. Reportedly, modified mesoporous silica film with pore sizes of 1 2 $\mathrm{nm}$ have been prepared on polymeric hollow fibers by static immersion in an acidic silica/surfactant precursor solution followed by a post-treatment of tetraethylorthosilicate (TEOS) vapor [24]. However, mesopores are too large for molecular separation and the thickness of the mesoporous silica layer can be as much as $1.6 \mu \mathrm{m}$, which may not be conducive to molecular diffusion in a dense separation layer.

Sol-gel processing is a well-established method for the preparation of hybrid organosilica films at low temperatures $\left(\sim 200^{\circ} \mathrm{C}\right)$, and is suitable for the deposit of organic-inorganic layered hybrid materials on various polymer substrates such as polymethylmetacrylate (PMMA), polyimide (PI), and polycarbonate (PC) [25-27]. These are typically prepared by a combination of metal alkoxides 
such as tetraethylorthosilicate (TEOS) and organoalkoxysilanes such as methyltriethoxysilane (MTES) or phenyltriethoxysilane (PTES) via sol-gel processing. In our previously mentioned study, we successfully fabricated a thin BTESE-derived silica layer on a non-porous PSF thin film via a sol-gel spin-coating process, which showed promise for large-scale industrial applications due to low cost and a simple fabrication process [22].

In this paper, we proposed a sol-gel spin-coating process for the preparation of porous polymer-supported organosilica layered hybrid membranes where the organosilica separation layer was deposited onto a porous polymeric support. First, we investigated the effective concentration of BTESE sol for the preparation of a uniform and complete BTESE layer on a non-porous polysulfone (NP-PSF) thin film; this BTESE layer was then deposited onto porous polysulfone ultrafiltration (PSF-UF) membranes. The PSF-UF-supported BTESE layered hybrid membranes were used for the vapor permeation dehydration of an isopropanol-water $(90 / 10 \mathrm{wt} \%)$ solution at $105^{\circ} \mathrm{C}$. Moreover, the single-gas permeance of this composite membrane was also investigated.

\section{Experimental}

\subsection{Materials}

Polysulfone (PSF) beads (CAS 25135-51-7; average $\left.\mathrm{M}_{\mathrm{n}}: \sim 22,000\right)$ were purchased from Aldrich and porous polysulfone ultrafiltration (UF-PSF) membranes provided by Nitto Denko (Japan) were used as a support. The 1,2-bis(triethoxysilyl)ethane (BTESE) precursor was purchased from Gelest, Inc. (Germany). N-methylpyrrolidone (NMP) and 1-propanol were of analytical grade and were purchased from Sigma-Aldrich and NacalaTesque, Inc., respectively. All chemicals were used without further purification.

\subsection{Sol preparation}

Nanometer-sized organosilica sols were synthesized via the hydrolysis and polymerization reaction of a precursor, 1,2-bis (triethoxysilyl)ethane (BTESE), in 1-propanol by following our previous report [22]. Briefly, a certain amount of BTESE was mixed with 1-propanol, and then distilled water and $\mathrm{HCl}$ were successively added to this solution under vigorous stirring. The 
molar ratio of BTESE: $\mathrm{H}_{2} \mathrm{O}: \mathrm{HCl}$ was 1: $60: 0.1$, and a 10.0 equivalent wt\% of BTESE was maintained in the sol. After continuous stirring for $1.5 \mathrm{~h}$ in a closed glass bottle at room temperature, the BTESE sols were diluted with 1-propanol to 2.5, 5.0, 7.5, and $10 \mathrm{wt} \%$ of BTESE.

\subsection{Deposition of the BTESE layer on non-porous PSF thin films}

For preparing non-porous polysulfone (NP-PSF) thin films on glass substrates, PSF beads and N-methylpyrrolidone (NMP) were loaded in a sealed glass bottle and stirred with a magnetic stirrer at $70^{\circ} \mathrm{C}$ for 3 hours until the PSF beads were completely dissolved at a PSF concentration of $15 \mathrm{wt} \%$. The PSF solution was spin-coated onto the glass substrate $(18 \mathrm{~mm} \times 18 \mathrm{~mm}$, thickness: $0.12 \mathrm{~mm}$ ) at $6,000 \mathrm{rpm}$ for 5 seconds and dried at $100{ }^{\circ} \mathrm{C}$ for $30 \mathrm{~min}$ to evaporate any residual solvent. A comparison of the FTIR spectrums of PSF beads and PSF film confirmed that the residual NMP in PSF film was fully removed (see Supplementary information). Finally, a transparent and smooth NP-PSF thin film was attached to the glass substrate (Fig.1a). Then, the BTESE sol was spin-coated onto the NP-PSF thin film as well as onto glass substrates. The spin speed was increased to 6,000 rpm in $5 \mathrm{~s}$ and was held for $30 \mathrm{~s}$ (Spin-coating process). Finally, the obtained BTESE/NP-PSF composite film was cured at $100^{\circ} \mathrm{C}$ for $25 \mathrm{~min}$ (Curing process). In addition, the thick BTESE film was prepared on a glass substrate via the drop-casting method, and then it was dried at $150{ }^{\circ} \mathrm{C}$ for $25 \mathrm{~min}$.

a

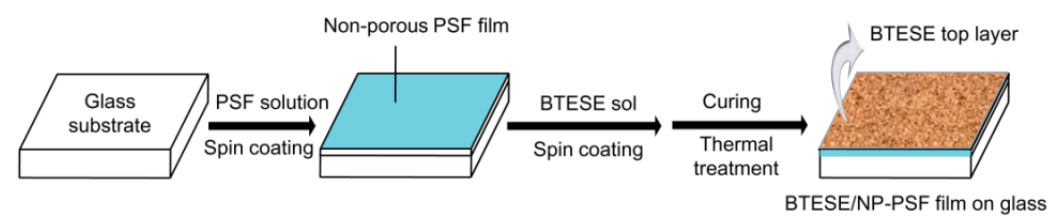

b
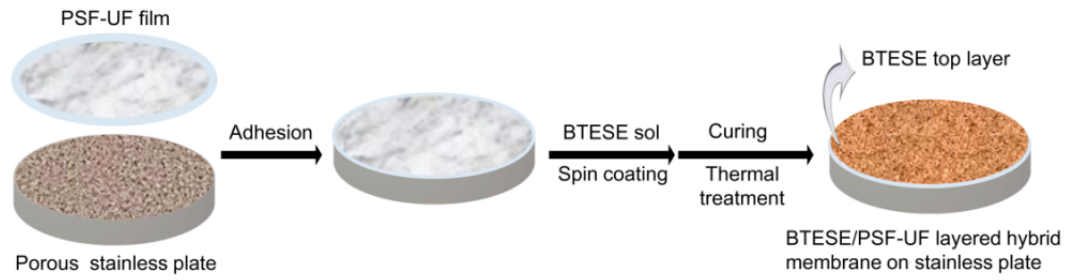

Fig. 1. A schematic illustration of the process for BTESE spin-coating on NP-PSF thin film (a) and porous PSF-UF support film (b). 
2.4 Deposition of the BTESE layer on a porous PSF substrate

Sol-gel spin coating of a BTESE layer on porous polysulfone ultrafiltration (PSF-UF) membranes was kindly supplied by Nitto Denko Co., Ltd., and was conducted using a similar process. First, in order to perform the spin-coating process, a porous PSF-UF membrane (Diameter: $2.5 \mathrm{~cm}$ ) was fixed onto a macroporous stainless plate (Pore diameter: $100 \mu \mathrm{m}$, porosity: 50\%), as shown in the schematic diagram (Fig.1b). Subsequently, approximately $200 \mu \mathrm{L}$ of BTESE sol (10 wt\%) was dropped onto this stainless plate-supported PSF-UF surface, and the spin speed was then increased to $6,000 \mathrm{rpm}$ in $5 \mathrm{~s}$ and was held for $30 \mathrm{~s}$ (Spin-coating process). Finally, obtained BTESE/PSF-UF layered hybrid membranes were cured at different temperatures $\left(100 \sim 200{ }^{\circ} \mathrm{C}\right)$ for $25 \mathrm{~min}$ (Curing process). One spin-coating cycle involved both spin-coating and curing processes. In vapor permeation and gas permeation experiments, the BTESE/PSF-UF layered hybrid membranes were always fixed onto the macroporous stainless plate, as described in Fig.1b.

\subsection{Characterizations}

Several methods were used to characterize the layered hybrid membranes consisting of organosilica BTESE layers on a PSF-UF support. For the BTESE/NP-PSF composite films, the water contact angle was accomplished using a Dropmaster (DM-300, Kyowa Co., Japan), and the surface topography was characterized with a scanning probe microscope (SPM, Nanocute, Sii, Japan). The morphology and thickness of BTESE layers on porous PSF-UF supports was examined using field-emission scanning electron microscopy (FE-SEM, Hitachi S-4800). The chemical structures of the surfaces of the layered hybrid membranes were measured by attenuated total reflection Fourier transform infrared spectroscopy (ATR-FT/IR-4100, JASCO, Japan). The membrane sample surface was measured by X-ray photoelectron spectroscopy (XPS, Shimadzu ESCA3400, Japan). The depth profiles of the concentrations of Si, S, C, and O in the membrane were obtained from the $\mathrm{C} 1 \mathrm{~s}, \mathrm{Si} 2 \mathrm{p}, \mathrm{O} 1 \mathrm{~s}$, and $\mathrm{S} 2 \mathrm{p}$ energy bands by sputtering with $0.6 \mathrm{keV} \mathrm{Ar}^{+}$at $80 \mathrm{~nm} \min ^{-1}$ (as $\mathrm{SiO}_{2}$ ). 


\subsection{Permeation experiment}

\subsubsection{Vapor permeation experiment}

Vapor permeation (VP) experiments on a $90 \mathrm{wt} \%$ IPA aqueous solution were performed using an apparatus equipped with a flat membrane module similar to a previously reported setup [28], as shown in Fig. 2a. The permeation cell of the flat membrane module (Effective area of membrane: $2.3 \mathrm{~cm}^{2}$ ) was placed in a forced-air-flow oven at $105{ }^{\circ} \mathrm{C}$ in order to ensure the complete vaporization of the feed solution before the permeation cell. Briefly, the line of the feed side was heated to $105{ }^{\circ} \mathrm{C}$ to vaporize the solution and the retentate stream was open to the atmosphere, while the permeate pressure was maintained at less than $1 \mathrm{kPa}$ under vacuum. The concentrations of the components in the feed and permeate were determined by gas chromatography (GC-14B, Shimadzu, Japan). The permeate flux of either the water or the IPA $\left(J(\mathrm{i}): \mathrm{kg} \mathrm{m}^{-2} \mathrm{~h}^{-1}\right)$ were calculated according to the following equation:

$J(\mathrm{i})=\frac{M(\mathrm{i})}{A t}$

where $M(\mathrm{i})$ is the mass of permeated i collected over time, $t$, and through the effective membrane area, $A$, the separation factor $(\alpha)$ was defined by the following equation:

$\alpha=\frac{Y_{\text {water }} / Y_{\text {IPA }}}{X_{\text {water }} / X_{\text {IPA }}}$

where $Y_{\text {water }}$ and $Y_{\text {IPA }}$ are the weight fractions of water and IPA in the permeate solution, respectively, and $X_{\text {water }}$ and $X_{\text {IPA }}$ are the weight fractions of water and IPA in the feed solution. 

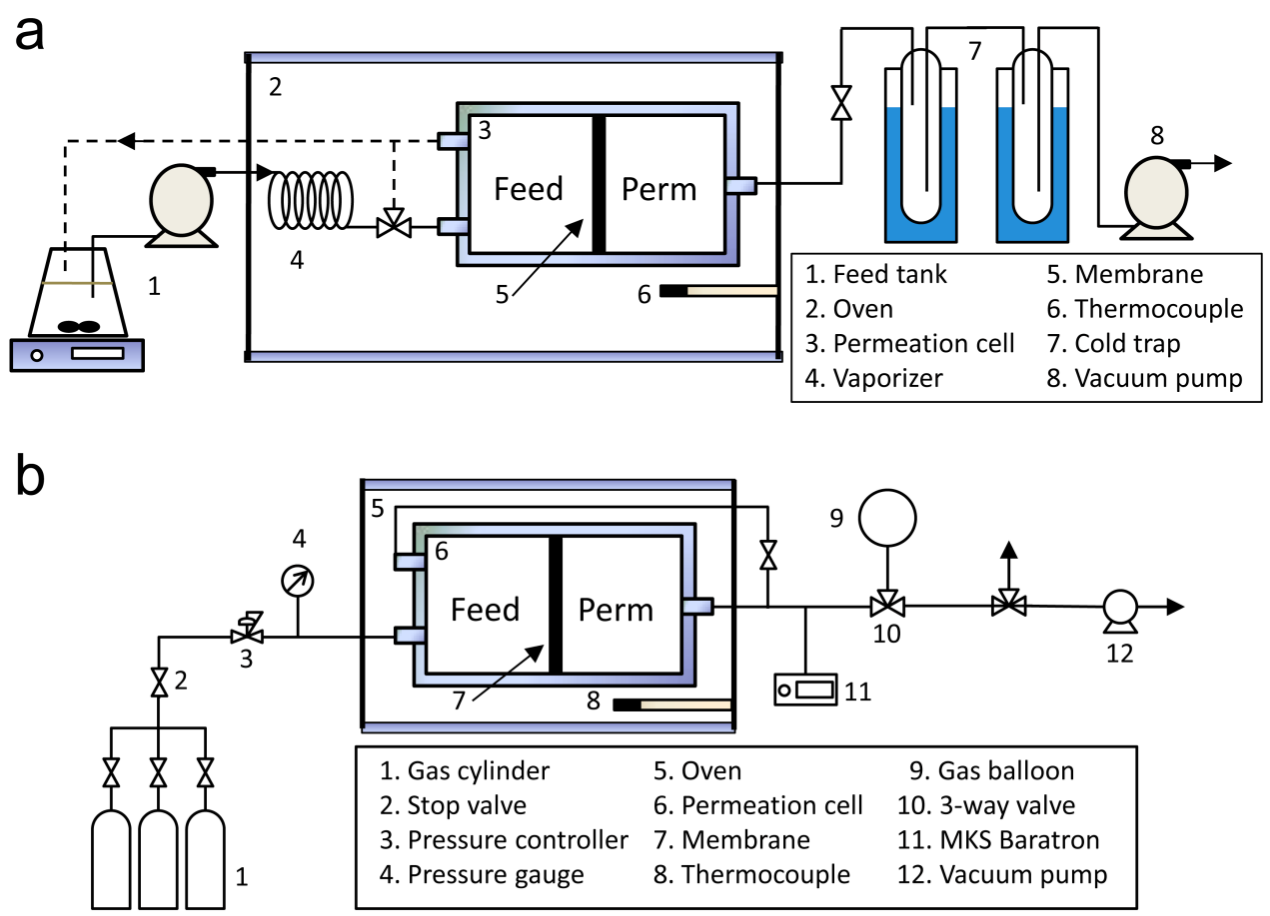

Fig. 2. Schematic diagrams of the VP (a) and gas permeance (b) experimental setup.

\subsubsection{Single-gas permeation experiment}

Single-gas permeation experiments of porous PSF-UF supports were performed using a stainless permeation cell at $105{ }^{\circ} \mathrm{C}$, as already described elsewhere [29]. Briefly, a high-purity single component gas $\left(\mathrm{He}, \mathrm{H}_{2}, \mathrm{~N}_{2}\right.$ or $\left.\mathrm{SF}_{6}\right)$ was fed into the membrane module and the feed gas pressure was set at 2.5 bar, while the pressure of the permeate side was maintained at atmospheric pressure. The permeation rate of the PSF-UF support was measured using a bubble flow meter. Before the measurement, membrane samples were pretreated under vacuum with a He flow for $1 \mathrm{~h}$ at $105^{\circ} \mathrm{C}$. The gas permeation of BTESE/PSF-UF layered hybrid membranes was determined via the constant-volume variable-pressure method using the apparatus shown in Fig. 2b. The pressure of the feed side $\left(p_{1}\right)$ was maintained at $105 \mathrm{kPa}$ and the permeate side was evacuated to $10 \mathrm{~Pa}$ before measurement. The pressure of the permeate side $\left(p_{2}\right)$ was measured using an MKS Baratron pressure transducer (type 722A) over the same time course. The fixed total volume of the permeate side, $V_{2}$, including permeation cell, lines and a glass balloon, was $1.40 \times 10^{-4} \mathrm{~m}^{3}$. The 
gas permeance $(P)$ was calculated using the following equation:

$P=\frac{V_{2}}{A R T} \frac{1}{\left(p_{2}-p_{1}\right)} \frac{d p_{2}}{d t}$

where $A$ is the effective area of the membrane, $R$ is the gas constant and $T$ is the temperature. Because the feed pressure ( $\left.p_{1}\right)$ was constant, equation (3) can be integrated into equation (4):

$P=\frac{V_{2}}{A R T \Delta t} \ln \frac{\left(p_{1}-p_{2,1}\right)}{\left(p_{1}-p_{2,2}\right)}$

where $p_{2,1}$ and $p_{2,2}$ are the permeate pressure at $t=t_{1}$ and $t=t_{2}=t_{1}+\Delta t$, respectively. Meanwhile, the gas selectivity for gases $i$ and $j\left(\alpha_{\mathrm{i} / \mathrm{j}}\right)$ were calculated using the following equation:

$\alpha(i / j)=\frac{P_{i}}{P_{j}}$

\section{Results and discussion}

3.1. The effect of sol concentration on the formation of a BTESE layer on non-porous PSF thin film

In a spin-coating process, it is generally not easy for low-viscous sols to form high-quality films because the high spreading rate leads to the instabilities taking place almost instantaneously. Therefore, the concentration of the coating sols significantly influences the formation of thin films. In the present study, before the deposition of BTESE film on porous PSF ultrafiltration (PSF-UF) supports, the effect of the concentration of BTESE sols on film formation on non-porous PSF (NP-PSF) thin films was investigated.

BTESE sols with different concentrations were spin-coated on NP-PSF thin films and glass substrates. Fig. 3 shows the water contact angle of BTESE films as a function of BTESE concentration for spin coating. As shown at a $0.0 \mathrm{wt} \%$ concentration of BTESE in Fig 3, the contact angles of a pristine hydrophobic NP-PSF thin film and a hydrophilic glass substrate were about $80^{\circ}$ and $14^{\circ}$, respectively. After the deposition of BTESE film on both substrates, their values of water contact angle tended to be consistent with an increase in sol concentration. In particular, when the concentration of the BTESE sol was $\geq 5.0 \mathrm{wt} \%$, both contact angles were identical at about $43^{\circ}$. This indicates that a complete and continuous BTESE film could be formed 
on both NP-PSF thin films and glass substrates when the concentration of a BTESE sol is $\geq 5.0$ wt \%. On the other hand, the topmost BTESE film on a substrate was formed only partially when the concentration of the BTESE sol was $2.5 \mathrm{wt} \%$, leading to different values for the contact angle of BTESE films on both substrates.

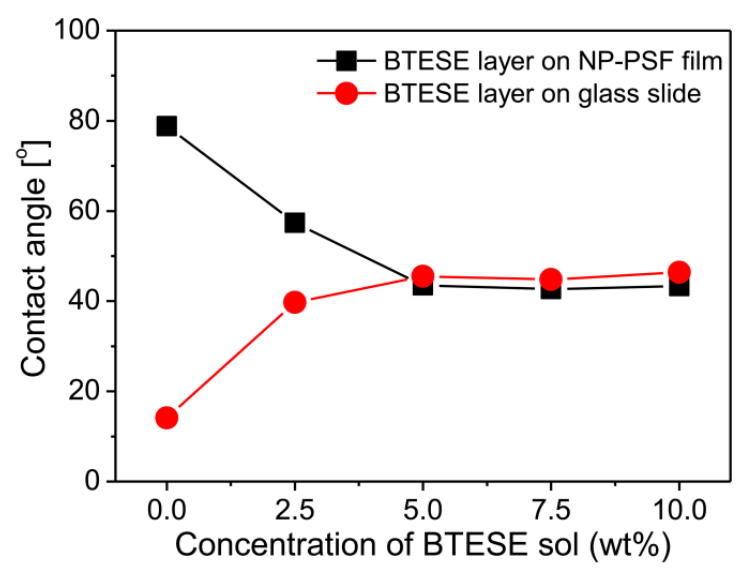

Fig. 3. Contact angle of BTESE films on NP-PSF thin films and glass sildes as a function of different concentrations of BTESE sols $\left(0.0,2.5,5.0,7.5\right.$ and $10.0 \mathrm{wt} \%$, curing temperature: $\left.100{ }^{\circ} \mathrm{C}\right)$.

In addition, the three-dimensional morphologies of BTESE-coated NP-PSF films with different concentrations of BTESE were measured using SPM, as shown in Fig. 4. It was clear that some isolated gibbosities (Diameter: $1 \sim 2 \mu \mathrm{m}$, height: $2 \sim 5 \mathrm{~nm}$ ) were observed on the film surfaces at low sol concentrations $(2.5 \mathrm{wt} \%)$, as shown in Fig. 4a. As sol concentrations increased, the gibbosities were gradually reduced and disappeared completely at high sol concentrations (7.5 or $10 \mathrm{wt} \%$ ), as shown in Fig. $4 \mathrm{c}$ and d. Our speculation as to the cause of this phenomenon follows. With the progress of spin coating, the solution film with a low concentration of BTESE sol on the substrate became thinner due to evaporation and tended to spontaneously separate, subsequently forming isolated and microscopic droplets. After complete evaporation of the solvent in the droplets, the gibbosities were finally formed, leading to the formation of discontinuous BTESE films. This inference was basically consistent with our contact angle experiment. Therefore, both experimental results suggest that the lowest concentration of BTESE sol that would effectively form a complete and continuous BTESE film on an NP-PSF thin film was $5.0 \mathrm{wt} \%$ under these spin-coating conditions. 


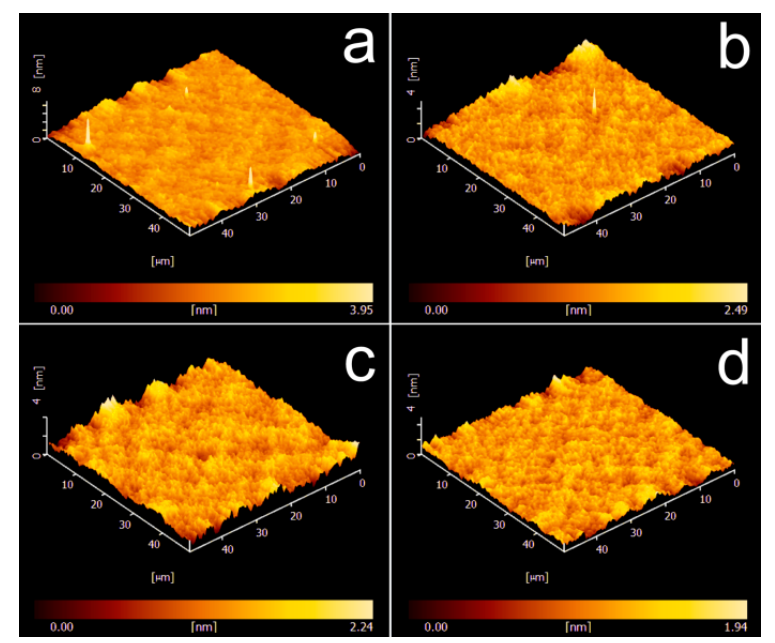

Fig. 4. SPM three-dimensional images of the surface of the BTESE film spin-coated on NP-PSF thin film with different concentrations of BTESE sol (2.5 (a), 5.0 (b), 7.5 (c) and 10.0 (d) wt\%).

\subsection{The effect of curing temperature on a porous PSF-UF support}

In the preparation process of PSF-UF-supported BTESE layered hybrid membranes, the curing temperature could influence the performance of the membrane, but high temperatures also may have an impact on the surface morphology and pore structure of a PSF-UF support. Therefore, the effect of curing temperature on a PSF-UF support was investigated, which was critical in determining the curing temperature of a PSF-UF-supported BTESE membrane.

The porous PSF-UF supports were placed in the oven at different temperatures (100, 150 and 200 ${ }^{\circ} \mathrm{C}$ ) for 25 minutes. Fig. 5 shows the SEM images of untreated and treated PSF-UF supports at high temperatures. It was clear that the pore size distribution of an original PSF-UF support was less than $50 \mathrm{~nm}$, as shown in Fig. 5a. In a similar manner, images of PSF-UF supports treated at 100 and $150{ }^{\circ} \mathrm{C}$ (Fig. $5 \mathrm{~b}$ and c) are similar to the original sample in terms of surface morphology and pore dimension. However, it was obvious that the image of a PSF-UF support treated at $200{ }^{\circ} \mathrm{C}$ (Fig.5 d) was different from the previous samples, which showed a smooth and non-porous surface, and that the pores were too small to be observed. This might have been because the thermal treatment temperature was higher than the glass transition temperature of 
polysulfone $\left(\mathrm{Tg}=185^{\circ} \mathrm{C}\right)[29]$. When polymers are used above $\mathrm{Tg}$, i.e., in a rubbery state, they either become elastic like rubber or they liquefy [30]. Therefore, porous PSF-UF supports would collapse and deform under their own gravity, leading to a reduction in the numbers of pores or pore sizes. Therefore, the results showed that the optimal curing temperature was $150^{\circ} \mathrm{C}$.

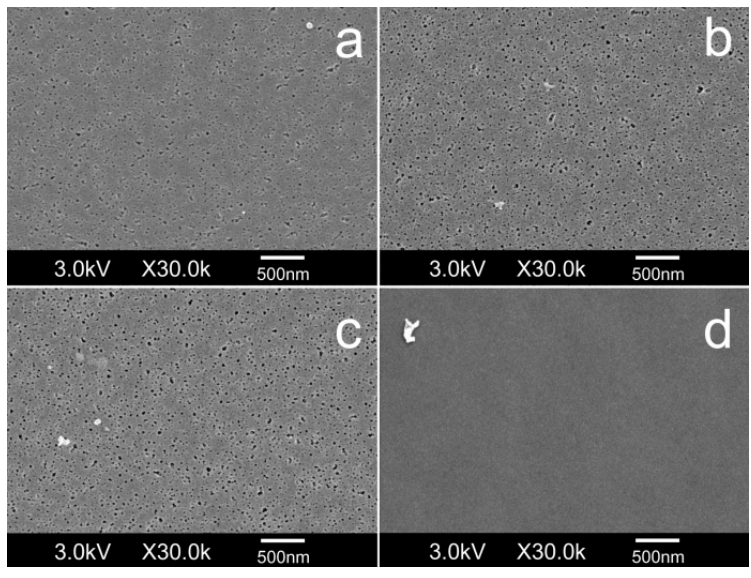

Fig. 5. SEM images of the surface morphology of untreated (a) and treated PSF-UF supports at the thermal treatment temperatures of 100 (b), 150 (c), and 200 (d) ${ }^{\circ} \mathrm{C}$.

3.3 Characteristics of PSF-UF-supported BTESE layered hybrid membranes

3.3.1 Morphologies of BTESE/PSF-UF layered hybrid membranes

The morphology of a coated BTESE layer was examined by FE-SEM. Fig. 6 shows the surface and cross-section morphologies of PSF-UF supports and BTESE/PSF-UF layered hybrid membranes prepared by 3 spin-coating cycles and cured at $150{ }^{\circ} \mathrm{C}$. It is obvious that the porous structure of the PSF-UF surface (Fig. 6a) disappeared on the surface of the BETSE/PSF-UF layered hybrid membrane. Instead, as shown in Fig. 6b, a uniform, dense and defect-free top layer was observed. The cross-section SEMs of PSF-UF supports before and after coating (Fig. 6c and d) showed BTESE layers with thicknesses of approximately 300 400 nm deposited onto the PSF-UF support surface. These demonstrate that the perm-selective BTESE layer was successfully prepared on PSF-UF supports. 


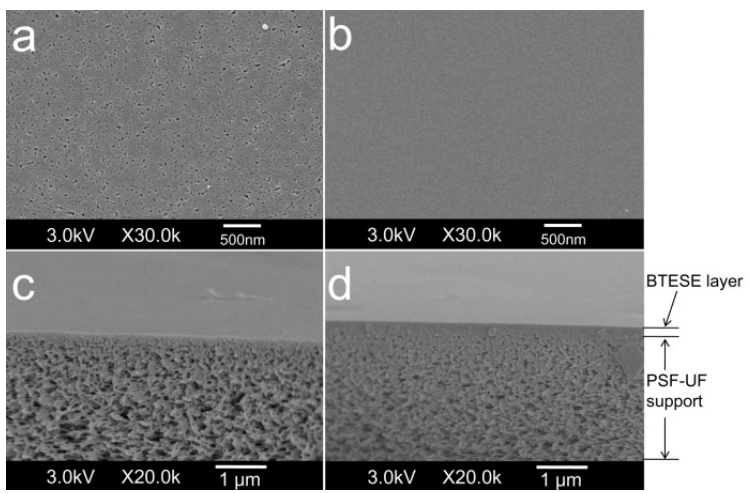

Fig. 6. SEM images of the surface and cross-section of a membrane. (a) Surface of a PSF-UF support, (b) surface of a BTESE/PSF-UF membrane, (c) cross-section of a PSF-UF support, and (d) cross-section of a BTESE/PSF-UF membrane (The BTESE/PSF-UF layered hybrid membrane was prepared by 3 spin-coating cycles, and the curing temperature was $\left.150^{\circ} \mathrm{C}\right)$.

\subsubsection{ATR-FTIR spectra of a BTESE/PSF-UF layered hybrid membrane}

Evidence of the chemical bonding of the BTESE film, the PSF-UF support, and the PSF-UF-supported BTESE layered hybrid membrane were analyzed via ATR-FTIR technique, which enabled a measurement of the IR absorption to the penetration depth of a few micron meters from the surface. Fig. 7 shows the ATR-FTIR spectrum of these samples. First, the typical characteristic absorption bands of PSF-UF support were observed for an aromatic ether group (1237 and $\left.1015 \mathrm{~cm}^{-1}\right)$, benzene ring $\left(1585\right.$ and $\left.1490 \mathrm{~cm}^{-1}\right)$, and sulfoxide group $\left(1080 \mathrm{~cm}^{-1}\right)$ [31]. Meanwhile, the FTIR spectrum of BTESE film was reported for Si-O-Si $\left(1000 \sim 1200 \mathrm{~cm}^{-1}\right)$ and Si-OH $\left(900 \sim 950 \mathrm{~cm}^{-1}\right)$ groups [12]. The FTIR spectra of BTESE/PSF-UF layered hybrid membrane revealed the presence of peaks associated with $\mathrm{Si}-\mathrm{O}-\mathrm{Si}$, although a broad peak appeared between 1000 1200 $\mathrm{cm}^{-1}$ at the overlap with the peaks of PSF-UF support in this region. Furthermore, another broad absorption band was observed in the $3100 \sim 3600 \mathrm{~cm}^{-1}$ range, which indicated the presence of hydroxyl groups (O-H: $\left.3450 \mathrm{~cm}^{-1}\right)$. In addition, a new peak appeared at $950 \mathrm{~cm}^{-1}$, and was also assigned to the Si-OH group. The spectra of ATR-FTIR confirmed that a BTESE layer had formed on the PSF-UF support. 


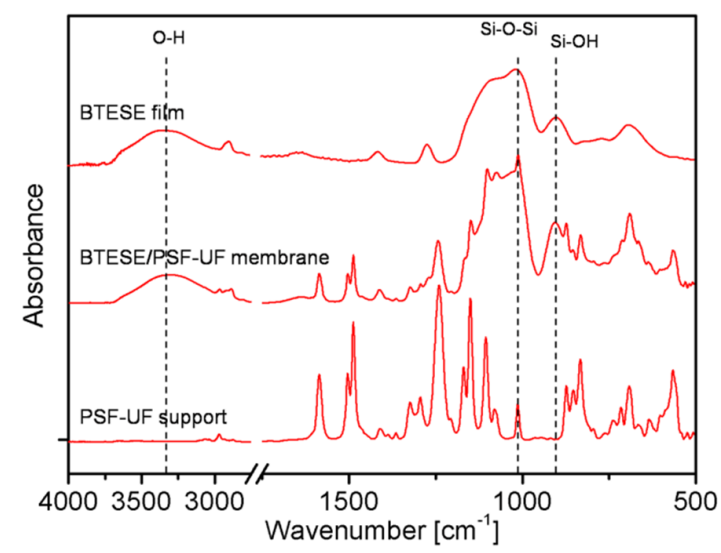

Fig. 7. The ATR-FTIR spectra of the BTESE film, the BTESE/ PSF-UF membrane, and the PSF-UF support (BTESE/PSF-UF membrane: 3 spin-coating cycles, curing temperature: $150^{\circ} \mathrm{C}$ ).

\subsubsection{XPS depth-profile analysis of a BTESE/PSF-UF layered hybrid membrane surface}

The XPS depth profile of a BTESE/PSF-UF layered hybrid membrane, which was prepared with 3 spin-coating cycles and cured at $150^{\circ} \mathrm{C}$, is shown in Fig. 8. The concentration of Si atoms that was attributed to the BTESE layer was detected on the layered hybrid membrane surface and showed a sharp decrease in depth at approximately $150 \mathrm{~nm}$. This indicated that the actual thickness of the BTESE layer on the PSF-UF support surface was about $150 \mathrm{~nm}$. Meanwhile, the concentration of S atoms, which was attributed to the PSF-UF support, was detected at the same depth and showed a slight increase as the depth increased. Moreover, a clear concentration change of $\mathrm{C}$ and $\mathrm{O}$ atoms was also found at a depth of approximately $150 \mathrm{~nm}$. Clearly, the $\mathrm{C}$ and $\mathrm{O}$ atoms detected at depths between 0 and $150 \mathrm{~nm}$ originated from the Si-C-C-Si and Si-O-Si bonds in the BTESE layer and those detected from 150 to $350 \mathrm{~nm}$ were from the $-\mathrm{C}_{6} \mathrm{H}_{5}$ and $-\mathrm{SO}_{2}$ - groups of the PSF-UF support. In addition, a low concentration of $\mathrm{Si}$ was observed at depths in the layer that were deeper than $150 \mathrm{~nm}$. Considering the large size of the pores in the PSF-UF support ( $\sim 50 \mathrm{~nm}$ diameter), we speculated that penetration of the BTESE sol into the support was inevitable. Furthermore, the composition of the top layer is worth noting. The network structure of the BTESE layer was composed of $\mathrm{Si}-\mathrm{O}-\mathrm{Si}$ and $\mathrm{Si}-\mathrm{C}-\mathrm{C}-\mathrm{Si}$ moieties; therefore, the atomic number ratio of $\mathrm{Si}, \mathrm{O}$ and $\mathrm{C}$ was $\mathrm{Si}_{2} \mathrm{O}_{3} \mathrm{C}_{2}$. The compositions of $\mathrm{Si}, \mathrm{O}$ and $\mathrm{C}$ obtained from the surface of a PSF-UF-supported BTESE layer were 29,44 and 27\%, respectively, which was roughly identical to the theoretical 
calculation values ( $\mathrm{Si} 28.6 \%$, O 43\%, and C 28.6\%).

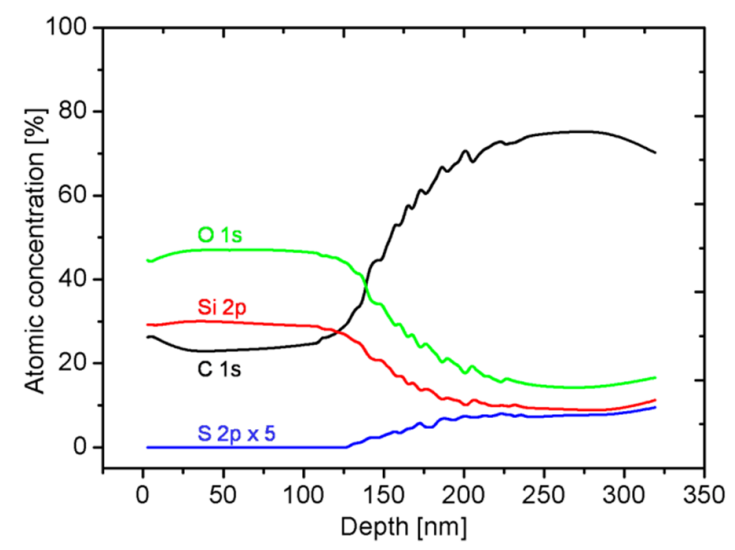

Fig. 8. XPS depth profile of C 1s, Si 2p, O 1s, and S 2p in the BTESE/PSF-UF layered hybrid membrane (BTESE/PSF-UF membrane: 3 spin-coating cycles, curing temperature: $150{ }^{\circ} \mathrm{C}$ ).

3.4 Vapor permeation performance of the membrane

Considering the large pore size of the PSF-UF support (50nm) and the XPS analysis, it is probable that a certain degree of penetration of BTESE sol into the support occurred. This might have resulted in a discontinuous BTESE layer during spin-coating when there was only one coating-curing cycle. Moreover, at least one report notes that multiple spin-coating cycles had filled the surface porosity associated with previously deposited layers [32]. Thus, the number of spin-coating cycles is expected to play a crucial role in avoiding the formation of defects in the PSF-UF supported BTESE layer, and will have a significant effect on the performance of a BTESE/PSF-UF layered hybrid membrane. Therefore, the separation performance of the BTESE/PSF-UF layered hybrid membrane was evaluated according to the dehydration of the IPA-water (IPA: $90 \mathrm{wt} \%$ ) solution via the vapor permeation (VP) process, and the effect of multiple spin-coating cycles was investigated for how it would affect the separation performance of this membrane. 

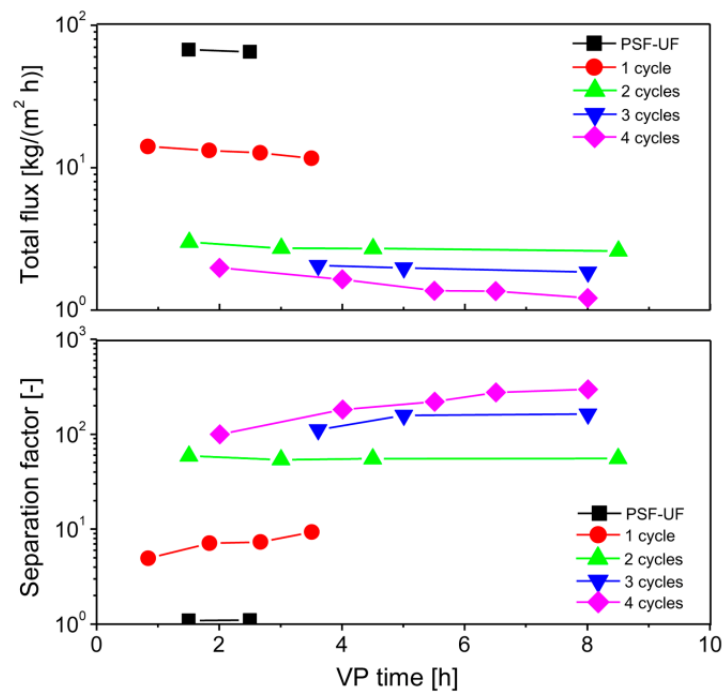

Fig. 9. Time course of VP performance for BTESE/PSF-UF layered hybrid membranes prepared with different spin-coating cycles (All the membranes were coated with 10\% BTESE sols, and were cured at $150{ }^{\circ} \mathrm{C}$ ).

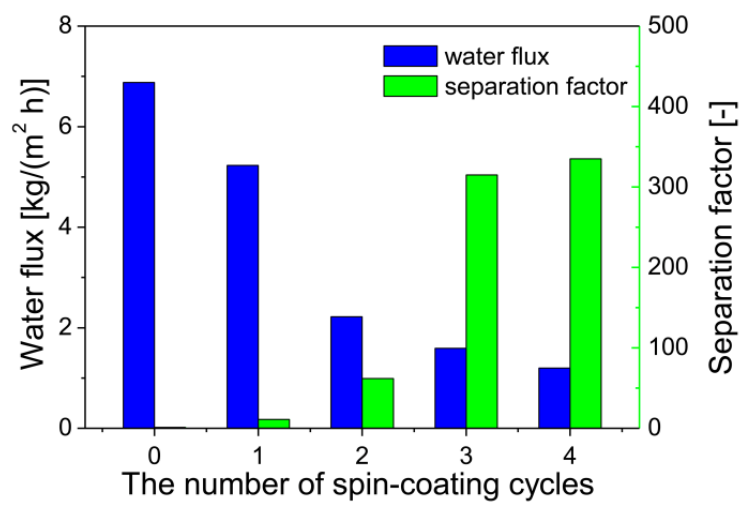

Fig. 10. The water flux and separation factor of BTESE/PSF-UF layered hybrid membranes for different spin-coating cycles (The VP performances were taken at the last points of the VP experiment of Fig. 9).

Fig. 9 shows the initial ten-hour time course of VP performance for the IPA/water mixture at 105 ${ }^{\circ} \mathrm{C}$ through BTESE/PSF-UF layered hybrid membranes prepared with different spin-coating cycles. It was obvious that the total flux for PSF-UF support was as high as $60 \mathrm{~kg} /\left(\mathrm{m}^{2} \mathrm{~h}\right)$ and that the water/IPA separation factor was very low, almost non-selective due to the large pore sizes. With an increase in the number of spin-coating cycles, particularly after one or two spin-coating cycles, the separation factor increased gradually, while the total flux of membranes decreased sharply. This result suggests that one or two spin-coating cycles resulted in a discontinuous BTESE layer, which 
did not completely cover the large pores of the PSF-UF surface, and led to high flux and low selectivity. Fig. 10 presents VP performance for the BTESE/PSF-UF layered hybrid membranes as a function of the spin-coating cycles. After three spin-coating cycles, the layered hybrid membrane gave a separation factor as high as 315 while the water flux decreased slightly. Moreover, compared with three spin-coating cycles, the separation factor of the membrane after four spin-coating cycles was not increased significantly while the water flux was further decreased because of a thicker BTESE layer. However, after further spin-coating cycles, the layered hybrid membranes often showed an increase in water flux and low separation factors. This might have been because the thicker BTESE layer on a PSF support was more liable to form cracks during the membrane assembly or operating processes. This result suggests that a thinner BTESE layer on a PSF support may provide better flexibility for a BTESE/PSF-UF layered hybrid membrane, which is quite important for further scale-up. Therefore, Fig. 6(b) and (d) and Fig. 10 indicate that a dense, continuous and defect-free BTESE layer was formed on the PSF-UF support surface after three spin-coating cycles, and drastically improved the water selectivity. Although the penetration of the BTESE sol into the pores of the support can be observed in Figs. 6d and 8, and possibly resulted in a relatively low water flux, the anchor-shaped structure formed in the interface between the BTESE layer and the PSF-UF support probably gave rise to a higher interfacial adhesion by the mechanical interlocking effect [33]. As shown in Fig. 9, the BTESE/PSF-UF layered hybrid membranes showed only a slight change in 10 hours, which confirmed that the PSF-UF-supported BTESE layer had a higher degree of stability during the operation process.

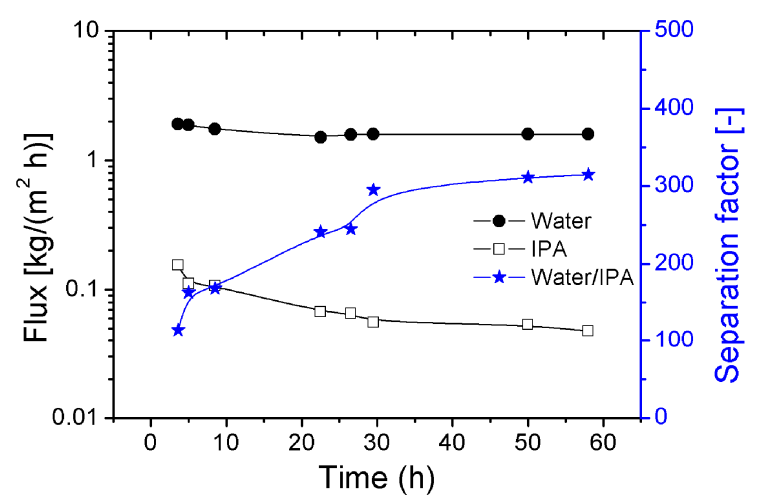

Fig. 11. Long-term time course for the VP performance of a BTESE/PSF-UF layered hybrid membrane (Three 
spin-coating cycles) for a water/IPA mixture (IPA: $90 \mathrm{wt} \%$ ) at $105^{\circ} \mathrm{C}$.

Membrane separation performance was investigated for long-term stability. Fig. 11 shows the time course of VP performance for a BTESE/PSF-UF layered hybrid membrane prepared by 3 spin-coating cycles; the vapor was created from a water/IPA mixture (IPA: $90 \mathrm{wt} \%$ ) at $105{ }^{\circ} \mathrm{C}$. This membrane showed a slight decrease in water flux for the first several hours, then reached a steady value of about $1.6 \mathrm{~kg} /\left(\mathrm{m}^{2} \mathrm{~h}\right)$ for as long as $60 \mathrm{~h}$. On the other hand, IPA flux gradually decreased for the initial 20 hours, resulting in a significant increase in the separation factor. Subsequently, IPA flux slowly decreased for an extended period of time, resulting in a gradual increase in the separation factor. A further reduction in IPA flux was probably due to the adsorption or reaction of IPA molecules by $-\mathrm{OH}$ groups in the pores of the BTESE layer, which would have resulted in smaller pores on the BTESE layer surface, thereby further preventing IPA molecules from permeating the layered hybrid membrane [34]. The BTESE/PSF-UF layered hybrid membranes exhibited excellent long-term stability (up to $60 \mathrm{~h}$ ), and the value of the separation factor reached as high as $\alpha($ water/IPA $)=315$.

\subsection{Single-gas permeance of a membrane}

Fig. 12 shows the single-gas permeance of $\mathrm{He}, \mathrm{H}_{2}, \mathrm{~N}_{2}$ and $\mathrm{SF}_{6}$ as a function of the kinetic diameter for a PSF-UF support and a BTESE/PSF-UF layered hybrid membrane at $105^{\circ} \mathrm{C}$. The PSF-UF support showed gas permeances as high as $10^{-5} \mathrm{~mol} /\left(\mathrm{m}^{2} \mathrm{~s} P a\right)$ and selectivities for $\mathrm{H}_{2} / \mathrm{N}_{2}$ of 3 and for $\mathrm{H}_{2} / \mathrm{SF}_{6}$ of 4 , which approximated Knudsen diffusion because of the large pore size. Gas permeances of the BTESE/PSF-UF layered hybrid membrane were decreased by approximately two orders of magnitude because of the presence of a perm-selective BTESE layer on the PSF-UF support. On the other hand, the separation for $\mathrm{H}_{2} / \mathrm{N}_{2}$ was increased by a factor of approximately $10 \sim 11$, which approximates that of BTESE membranes prepared on an $\alpha-\mathrm{Al}_{2} \mathrm{O}_{3}$ support [12]. This confirmed the successful formation of a BTESE layer on a PSF-UF support. Moreover, Table. 1 summarizes the water and IPA permeances of a BTESE/PSF-UF layered hybrid membrane during the VP experiment. It was interesting that the permeance of water vapor was approximately one order of magnitude higher than the permeance of gases, such as $\mathrm{He}$ and $\mathrm{H}_{2}$, 
with similar kinetic diameters. This result was similar to that of a BTESE membrane prepared on $\alpha-\mathrm{Al}_{2} \mathrm{O}_{3}$ [35]. One possibility could have been the presence of the $\mathrm{Si}-\mathrm{OH}$ groups in BTESE networks, which improved the $\mathrm{H}_{2} \mathrm{O}$-affinity of the membrane [20], and consequently enhanced the diffusion of water molecules through the membrane, resulting in high water permeability. This result would confirm the idea that the separation characteristics of these membranes for gas separation can mainly be attributed to the top BTESE layer.

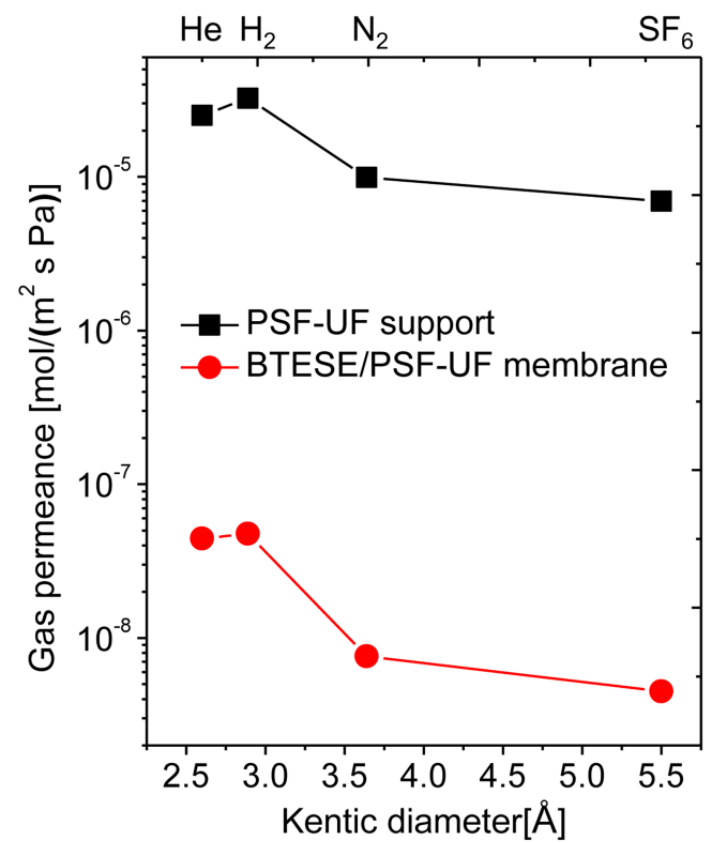

Fig. 12. Single-gas permeation of the PSF-UF support and BTESE/PSF-UF layered hybrid membrane (Three spin-coating cycles), as measured at $105^{\circ} \mathrm{C}$.

Table 1 Water/IPA separation performance of PSF-UF support and BTESE/PSF-UF layered hybrid membrane

\begin{tabular}{lllll}
\hline Membrane & Total flux & Water permeance & IPA permeance & Separation factor \\
& {$\left[\mathrm{kg} /\left(\mathrm{m}^{2} \mathrm{~h}\right)\right]$} & {$\left[\mathrm{mol} /\left(\mathrm{m}^{2} \mathrm{~s} \mathrm{~Pa}\right)\right]$} & {$\left[\mathrm{mol} /\left(\mathrm{m}^{2} \mathrm{~s} \mathrm{~Pa}\right)\right]$} & $\alpha$ (water/IPA) $[-]$ \\
\hline UF-PSF & 63.73 & $3.93 \times 10^{-6}$ & $3.60 \times 10^{-6}$ & 1 \\
BTESE/UF-PSF & 1.64 & $9.07 \times 10^{-7}$ & $3.03 \times 10^{-9}$ & 315 \\
\hline
\end{tabular}

\section{Conclusions}


A uniform, continuous and defect-free organosilica layer derived from 1,2-bis(triethoxysilyl)ethane (BTESE) was successfully deposited onto porous polysulfone ultrafiltration (PSF-UF) supports via a sol-gel spin-coating process to form a layered hybrid membrane where BTESE-derived silica layers were formed on a polymer support. The effective concentration for a BTESE sol was obtained along with both an optimal curing temperature and the number of spin-coating cycles. Compared with the original PSF-UF support, the layered hybrid organosilica/PSF-UF membrane showed an improved separation performance, which was ascribed to the molecular sieve effect of the deposited layer. The best vapor permeation (VP) performance was obtained using a perm-selective BTESE layer deposited onto a PSF-UF support with a corresponding water flux of $1.6 \mathrm{~kg} /\left(\mathrm{m}^{2} \mathrm{~h}\right)$ and a separation factor of 315 . Furthermore, the BTESE/PSF-UF layered hybrid membranes also exhibited good long-term stability. In addition, this layered hybrid membrane showed improved gas separation performance with moderate separation factors $(\approx 10)$ for $\mathrm{H}_{2} / \mathrm{N}_{2}$.

\section{Acknowledgement}

This work was supported in part by the Core Research of Evolutional Science and Technology program (CREST) from the Japan Science and Technology Agency (JST) and JSPS KAKENH Grant.

\section{References}

[1] S. Sommer, T. Melin, Design and Optimization of Hybrid Separation Processes for the Dehydration of 2-Propanol and other Organics, Ind. Eng. Chem. Res. 43 (2004) 5248-5259.

[2] N.N. Li, A.G. Fane, W.W. Ho, T. Matsuura (Eds.), Advanced membrane technology and applications, (2011) John Wiley \& Sons.

[3] B. Van der Bruggen, Integrated Membrane Separation Processes for Recycling of Valuable Wastewater Streams: Nanofiltration, Membrane Distillation, and Membrane Crystallizers Revisited, Ind. Eng. Chem. Res. 52 (2013) 10335-10341.

[4] K. Mohanty, M.K. Purkait, Memberane Technologies and Applications, (2011) CRC Press. 
[5] B. Van der Bruggen, J.C Jansen, A. Figoli, J. Geens, K. Boussu, E. Drioli, Characteristics and performance of a 'universal' membrane suitable for gas separation, pervaporation and nanofiltration applications, J. Phys. Chem. B. 110 (28) (2006) 13799-13808.

[6] H.L. Castricum, A. Sah, R. Kreiter, D.H.A. Blank, J.F. Ventec, J.E. ten Elshof, Hybrid ceramic nanosieves: stabilizing nanopores with organic links, Chem. Commun. (2008) $1103-1105$.

[7] H.L. Castricum, G.G. Paradis, M. C. Mittelmeijer-Hazeleger, R. Kreiter, J.F. Vente, J.E. ten Elshof, Tailoring the Separation Behavior of Hybrid Organosilica Membranes by Adjusting the Structure of the Organic Bridging Group, Adv. Funct. Mater. 21(2011) 2319-2329.

[8] H.L. Castricum, A. Sah, R. Kreiter, D.H.A. Blank, J.F. Ventec, J.E. ten Elshof, Hydrothermally stable molecular separation membranes from organically linked silica, J. Mater. Chem.18 (2008) 2150-2158.

[9] M. Kanezashi, K. Yada, T. Yoshioka, T. Tsuru, Design of Silica Networks for Development of Highly Permeable Hydrogen Separation Membranes with Hydrothermal Stability, J. AM. CHEM. SOC. 131 (2009) 414-415.

[10] T. Tsuru, T. Shibata, J. Wang, H.R. Lee, M. Kanezashi, T. Yoshioka, Pervaporation of acetic acid aqueous solutions by organosilica membranes, J. Membr Sci. 421-422 (2012) 25-31.

[11] R. Xu, J. Wang, M. Kanezashi, T. Yoshioka, T. Tsuru, Development of Robust Organosilica Membranes for Reverse Osmosis, Langmuir. 27 (2011) 13996-13999.

[12] J.H. Wang, M. Kanezashi, T. Yoshioka, T. Tsuru, Effect of calcination temperature on the PV dehydration performance of alcohol aqueous solutions through BTESE-derived silica membranes, J. Membr. Sci. 415-416 (2012) 810-815.

[13] R. Kreiter, M. D. A. Rietkerk, H. L. Castricum, H. M. van Veen, J. E. ten Elshof, J. F. Vente, Evaluation of hybrid silica sols for stable microporous membranes using high-throughput screening, J Sol-Gel Sci Technol. 57 (2011) 245-252.

[14] G. Li, M. Kanezashi, T. Tsuru, Preparation of organic-inorganic hybrid silica membranes using organoalkoxysilanes: The effect of pendant groups, J. Membr Sci. 379 (2011) 287-295.

[15] I. Agirre, P.L. Arias, H.L. Castricum, M. Creatoree, J.E. ten Elshof, G.G. Paradis, P.H.T. Ngamou, H.M. van Veen, J.F. Vente, Hybrid organosilica membranes and processes: Status and outlook, Sep. Sci. Technol. 121 (2014) 2-12. 
[16] K. Shqau, M. L. Mottern, D. Yu, H. Verweij, Preparation and Properties of Porous a- $\mathrm{Al}_{2} \mathrm{O}_{3}$ Membrane Supports, J. Am. Ceram. Soc. 89 [8] (2006) 1790-1794.

[17] H.F. Qureshi, A. Nijmeijer, A.J.A. Winnubst, Influence of sol-gel process parameters on the micro-structure and performance of hybrid silica membranes, J. Membr. Sci. 446 (2013) $19-25$.

[18] M. Kanezashi, M. Kawano, T.Yoshioka, T. Tsuru, Organic-Inorganic Hybrid Silica Membranes with Controlled Silica Network Size for Propylene/Propane Separation, Ind. Eng. Chem. Res. 51 (2012) 944-953.

[19] A.J. Burggraaf, L. Cot, Fundamentals of Inorganic Membrane Science and Technology. 1st Ed. Netherland: 1996.

[20] R. Xu , M. Kanezashi , T. Yoshioka, T. Okuda, J. Ohshita , T. Tsuru, Tailoring the Affinity of Organosilica Membranes by Introducing Polarizable Ethenylene Bridges and Aqueous Ozone Modification, ACS Appl. Mater. Interfaces 5 (2013) 6147-6154.

[21] P.H.T. Ngamou, J.P. Overbeek, R. Kreiter, H.M. van Veen, J.F. Vente, I.M. Wienk, P.F. Cuperusc, M. Creatore, Plasma-deposited hybrid silica membranes with a controlled retention of organic bridges, J. Mater. Chem. A. 1 (2013) 5567-5576.

[22] G.H. Gong, J. Wang, H. Nagasawa, M. Kanezashi, T. Yoshioka, T. Tsuru, Sol-gel spin coating process to fabricate a new type of uniform and thin organosilica coating on polysulfone film, Mater. Lett. 109 (2013)130-133.

[23] G. Dubois, W. Volksen, T. Magbitang, M.H. Sherwood, R.D. Miller, D.M. Gage, R.H. Dauskardt, Superior mechanical properties of dense and porous organic/inorganic hybrid thin films, J. Sol-Gel Sci. Technol. 48 (2008) 187-193.

[24] K.S. Jang, H.J. Kim, J.R. Johnson, W. Kim, W.J. Koros, C.W. Jones, S. Nair, Modified Mesoporous Silica Gas Separation Membranes on Polymeric Hollow Fibers, Chem. Mater. 23 (2011) 3025-3028.

[25] M.S. Lee, N.J. Jo, Coating of Methyltriethoxysilane-Modified Colloidal Silica on Polymer Substrates for Abrasion Resistance, J Sol-Gel Sci Technol. 24 (2002) 175-180.

[26] M. Hashizume, M. Hirashima, Sol-gel titania coating on unmodified and surface-modified polyimide films, J Sol-Gel Sci Technol. 62 (2012) 234-239.

[27] Y. Mizuta, Y. Daiko, A. Mineshige, T. Yazawa, Effect of plastics substrate on phase 
separation behavior and adhesion for $\mathrm{RSi}\left(\mathrm{OC}_{2} \mathrm{H}_{5}\right)_{3}-\mathrm{Si}\left(\mathrm{OC}_{2} \mathrm{H}_{5}\right)_{4}$ coatings prepared by sol-gel process, Ceram. Int. 39 (2013) 925-930.

[28] J. Albo, J. Wang, T. Tsuru, Application of interfacially polymerized polyamide composite membranes to isopropanol dehydration: Effect of membrane pre-treatment and temperature, J. Membr. Sci. 453 (2014) 384-393.

[29] J. Albo, J. Wang, T. Tsuru, Gas transport properties of interfacially polymerized polyamide composite membranes under different pre-treatments and temperatures, J. Membr. Sci. 449 (2014) 109-118.

[30] J. Rieger, The glass transition temperature Tg of polymers - Comparison of the values from differential thermal analysis (DTA, DSC) and dynamic mechanical measurements (torsion pendulum), Polym.Test. 20 (2001) 199-204.

[31] B.J. Gao, L. Fang, R.X. Zhang, J.Y. Men, Preparation of aromatic carboxylic acid-functionalized polysulfone and preliminary exploration of florescence emission character of formed polymer-rare earth complexes, Synth. Met. 162 (2012) 503-510.

[32] M.M. Elbaccouch, S. Shukla, N. Mohajeri, S. Seal, A. T-Raissi, Microstructural analysis of doped-strontium cerate thin film membranes fabricated via polymer precursor technique, Solid State Ionics 178 (2007) 19-28.

[33] W. Wei, S. Xia, G. Liu, X. Gu, W. Jin, N. Xu, Interfacial Adhesion Between Polymer Separation Layer and Ceramic Support for Composite Membrane, AIChE. 56(6) (2010) 1584-1592.

[34] J. Yang, T. Yoshioka, T. Tsuru, M. Asaeda, Pervaporation characteristics of aqueous-organic solutions with microporous $\mathrm{SiO}_{2}-\mathrm{ZrO}_{2}$ membranes: Experimental study on separation mechanism, J. Membr. Sci. 284 (2006) 205-213.

[35] R. Xu, J. Wang, M. Kanezashi, T. Yoshioka, T. Tsuru, Reverse Osmosis Performance of Organosilica Membranes and Comparison with the Pervaporation and Gas Permeation Properties, AIChE. 59(4) (2013) 1298-1307. 


\section{Layered hybrid membranes}

\section{1,2-bis(triethoxysilyl)ethane (BTESE)-derived $\mathrm{SiO}_{2}$ was} deposited on porous polysulfone ultrafiltration supports
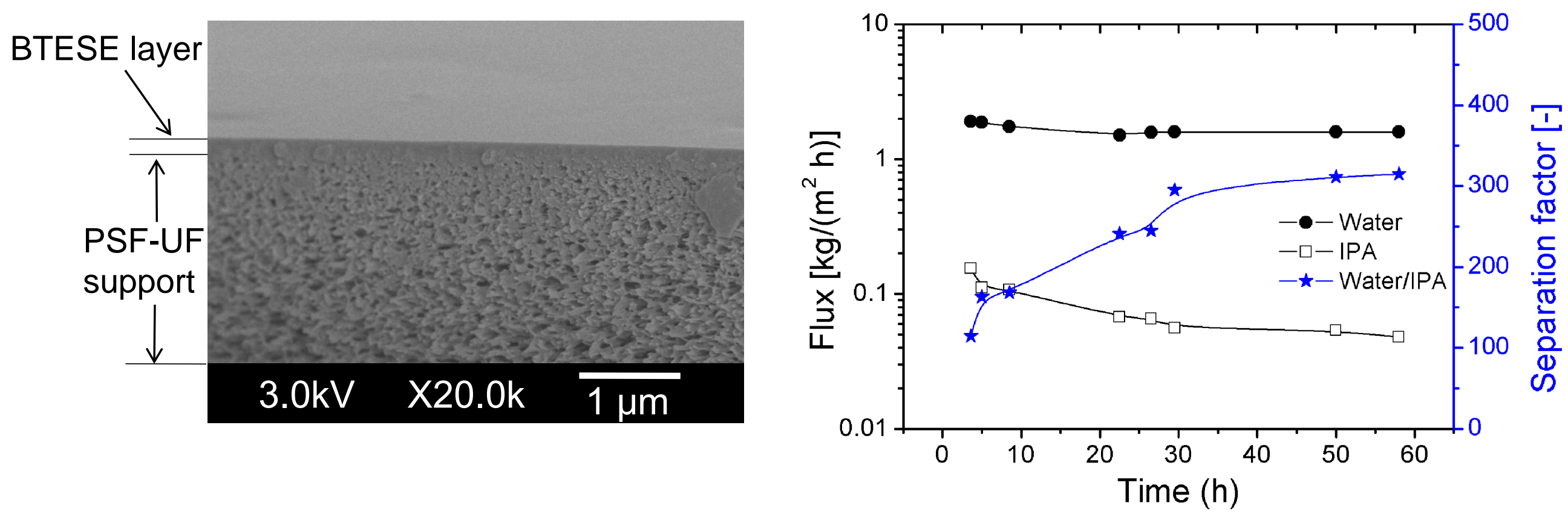